\title{
VIRTUAL SCREENING AND IDENTIFICATION OF PLAUSIBLE NOVEL THERAPEUTIC EGFR INHIBITORS AGAINST BREAST CANCER
}

\author{
Megana KSNM, Suneetha $Y^{*}$
}

Department of Zoology, Sri Venkateswara University, Tirupati 517502.

Received - March 26, 2021; Revision - July 09, 2021; Accepted - August 15, 2021

Available Online-August 30, 2021

DOI: http://dx.doi.org/10.18006/2021.9(4).481.491

\section{KEYWORDS \\ TNBC \\ Computational tools \\ Docking \\ In silico inhibition \\ Natural compounds}

\begin{abstract}
Present days increasing concern about the identification of potential non-toxic drug candidates against several cancers is very important. The current study was carried out to discover the novel phytochemicals as effective anticancer agents against the selected protein (i.e., EGFR), which is a promising target for moderating triple-negative breast cancer (TNBC). Various studies showed that the natural constituents have a strong anti-tumor capacity and inhibiting tumor growth. Here structure-based virtual screening and molecular docking studies have been recognized as rational tactics for the recognition of novel drug candidates against the binding domain of EGFR (PDB code: 3GKW \& 5FEE). Furthermore, the drug-likeness, adverse effects, and toxicogenomics effects were assessed with the help of various computational tools. Virtual screening was reported that 4 drug candidates i.e., CID: 65064; CID: 5280443; CID: 440735, and CID: 5280343 showed reliable consequences with fewer side effects and more efficient for the selected proteins. The overall effects indicated that renowned hits could be developed as reference skeletons for novel inhibitors envisaging EGFR to ameliorate TNBC.
\end{abstract}

* Corresponding author

E-mail: ysuneethareddy4@gmail.com (Dr. Y. Suneetha)

Peer review under responsibility of Journal of Experimental Biology and Agricultural Sciences.

Production and Hosting by Horizon Publisher India [HPI] (http://www.horizonpublisherindia.in/).

All rights reserved.
All the articles published by Journal of Experimental Biology and Agricultural Sciences are licensed under a Creative Commons Attribution-NonCommercial 4.0 International License Based on a work at www.jebas.org.

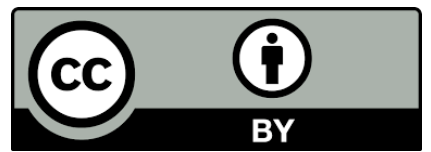




\section{Introduction}

Breast carcinoma is the most prevalent disease in females around the world and it is the third deadliest cancer after lung and cervical cancers (Benson et al., 2012). Various factors including biological, genetic, and environmental factors are intricate in the progression of breast malignancy. Age, hormonal replacement therapy, family history, Obesity, genetic changes, etc., are some of the general factors that confer the threat of breast carcinoma (WHO 2014). According to the data from the IARC registry assessed new female breast cancer cases in the year, 2020 is $11.7 \%$, and $6.9 \%$ of breast cancer-related death occurs in low-and middle-income economies (Hyuna et al., 2021). Under the data from ICMR-PBCR, carcinoma of the breast is common among women living in Indian states and metropolitan cities like Delhi, Kolkata, and Mumbai (National Centre Registry Programme 2016). The above reports powerfully recommend the implications of lifestyle factors as the most providers to develop breast cancer.

Usually, the dysregulation of the steroid hormones estrogen (ER), and progesterone $(\mathrm{PgR})$ is associated with the risk of breast tumors. The family comprises 4 receptors EGFR1, Her2, Her3, and Her4. Epidermal growth factor receptors are highly expressed in tumors of breast cancer, pancreas, head, prostate, ovarian, and colon cancer. The overexpression of EGFRs relates to the pathogenesis and development of several human cancers, which make them good therapeutic targets for both diagnosis and therapy (Dai et al., 2016; Amaia et al., 2019).

Phytochemicals are naturally active non-nutritive chemicals. Nowadays, natural compounds are frequently investigated in modern medicine. Numerous reports have suggested that dietary compounds such as fiber, lignin's, phytoestrogens, soy protein, phenols, fruits, etc., can play a prominent role in cancer treatment and prevention (Alok et al., 2019). Presently most of the efficacious anti-cancer drugs are derived from traditional compounds or their analogs. The eating of raw vegetables and vitamin-rich fruits are useful for control the risk of breast cancer.

One of the active compounds used to treat cancer is eriodictyol (ER) [(S)-2-(3, 4-dihydroxy phenyl)-5,7-dihydroxychroman-4one), a natural flavonoid compound (Marin et al., 2017), and a bitter-masking flavone, which is extracted from the plant Eriodictyon californicum. The compound is found in Eupatorium arnottianum (Clavin et al., 2007) and its glycosides (eriocitrin) on rose hips (Rosa canina). Other natural plant-derived compounds that can be used for breast cancer treatment are EGCG, resveratrol, quercetin, curcumin, apigenin, daidzein, etc., (Wamidh et al., 2020). EGCG is a powerful antioxidant, and it has been used as a breast cancer chemopreventive phytochemical candidate found in green tea (Camellia sinensis (Theaceae) (Sumio et al., 2020). EGCG (-)-Epigallo Catechin gallate, (-) -Epicatechin gallate
(EGC), EGC, and Epicatechin (EC) are the important polyphenol natural compounds which are reported in high quality in green tea (Yao et al., 2008; Lambert \& Elias, 2010; Musial et al., 2020).

Resveratrol (trans-3, 4', 5-trihydroxy stilbene) is a member of the stilbene family and it's also a polyphenol compound like flavonoids. Resveratrol was first discovered longer than sixty years ago by Takaoka, in the cohesive substance of Veratrum grandiflorum oleo's (John 2019). RES is highly available in dietary foods, including grapes, peanuts, berries, red wine, dark chocolate, and traditional oriental medicinal plants (Berman et al., 2017; Bahare et al., 2018; Xiao et al., 2019). High RES (resveratrol) concentrations are present in grapes, perhaps because of Vitis vinifera, which are responsive to fungal infections ( $\mathrm{Li}$ et al., 2015; Nawaz et al., 2017). Many scientific reports concluded that RES has shown several beneficial effects on the health of human beings and could be useful to defend against several pathologies (Wahab et al., 2017; Abhay et al., 2018). RES also acts as a preventive and chemotherapeutic agent against various human disorders (Sinha et al., 2016). Various wet biology experiments have been described that the RES exhibits activation in both hormonal sensitivity and resistance in breast cancer cells. This bioactive molecule is a potential phytoestrogen and acts as an agonist and antagonist for control ER+ breast carcinoma (Sandi pan et al., 2013; Roca et al., 2014). Hence, the prediction of novel potential drug candidates is very essential for future utilization. The selected natural ligands: Eriodictyol (Pubchem CID: 440735); Resveratrol (CID: 445154); Epigallo Catechin 3-gallate (CID: 65064); Piceatannol (CID: 667639); p-Coumarin acid (CID: 637542); Curcumin (CID: 969516); Quercetin (CID: 5280343); Apigenin (CID: 5280443); Daidzein (CID: 5281708) has outstanding anti-cancer activity, better PK, and ADMET properties. Based on their parameters, these phytochemicals were chosen for the current study. This study aimed to predict the best breast cancer inhibitors by using in silico studies and exploration of the molecular docking simulations against the selected EGFR receptors.

\section{Materials and methods}

\subsection{Structure Retrieval}

A crystallographic macromolecular structure of EGFR (Epidermal growth factor receptor) was downloaded from PDB (www.rcsb.org/pdb). The structure identified in PDB by the ID of 5FEE and $3 \mathrm{GKW}$, Res: $1.85 \AA$ \& $2.70 \AA$ as receptor models for docking studies.

\subsection{Retrieval of ligands}

The structure of all compounds in this study was retrieved from the Pub Chem compound database (http://pubchem.ncbi.nlm.nih.gov/). 
The selected chemical structures were downloaded in 3D SDF file format. After that, the downloaded molecules were minimized by using the Software open Babel, and the energy difference is less than 0.1. All the optimized ligands were converted to PDBQT format in the Pyrx Interface for docking studies.

\subsection{Molecular docking simulations and grid parameter file}

Molecular screening is the most important approach in the structurebased drug designing process (Dallakyan \& Olson, 2015). Docking simulation studies were done using the AD Vina in PyRx interface open-source software for selected optimized hits against the active site of the macromolecule. The active site dimensions selected as a grid center $\mathrm{x}=-3.6117, \mathrm{y}=18.9549, \mathrm{z}=-21.7196$, and grid dimensions $\mathrm{x}=43.1664 \AA, \mathrm{y}=47.1486, \AA \mathrm{z}=59.2543 \AA$ for 5FEE; While for 3GKW the active site dimensions as a grid center $\mathrm{x}=2.8973$, $\mathrm{y}=-$ 5.4929, $\mathrm{z}=-17.4551$ and grid dimensions $\mathrm{x}=71.1868 \AA$, $\mathrm{y}=54.1961 \AA, \mathrm{z}=45.2106$ and the free energy function and Lamarckian genetic algorithm were used for docking with 8 exhaustiveness iteration for every selected ligand poses. The Root mean square deviation value 0.0 with binding energy was considered as the best docking fit for ligand and macromolecule interactions. The grid parameters that are essential to creating such a grid were stored in the Grid Parameter File with GPF extension. The grid dimensions of both the macromolecules are shown in figure 1 .

\subsection{Hydrogen bond and molecular interaction analysis}

The receptor and ligand molecule interactions were investigated by using the software tool Pymol molecular viewer (Lill \& Danielson, 2011; Pymol 2015). The better affinity compounds were evaluated along with hydrogen bond interactions, and interaction residues with atoms involved in hydrogen bonds for both the macromolecule and chemical compounds. Because hydrogen bond interactions are involved in molecular stabilization and lead to function by interaction.

\subsection{Screening of bioactive ligands on the principle of RO5}

The selected bioactive compounds were screened on the premise of Pfizer's lead of five criteria i.e. the drug candidates have the number of $\mathrm{HBA} \leq 10, \mathrm{HBD}$ is not more than 5, Partition coefficient $\log \mathrm{P}$ under five( $\leq 5)$, and $\mathrm{MW} \leq 500$ Daltons (Lipinski et al., 2001). Other parameters such as water partition coefficient, volume, rotatable bonds, number of atoms, violations, drug-likeness, drug score, ADME, etc. were predicted using in silico methods. The best binding affinity values of ligands with the target receptors were investigated for its drug parameters, and adverse effects with the help of five different bioinformatics analytical tools, i.e., Admet Sar tool an inclusive source and free online tool for calculation of ADMET parameters available at http://lmmd.ecust.edu.cn/admetsar (Cheng et al., 2012), Molinspiration (http://www.molinspiration.com/), Swiss ADMEonline tool (http://www.swissadme.ch/index.php) (Daina et al., 2017), DruLiTo and OSIRIS property explorer programs, respectively.

\section{Results and Discussion}

\subsection{Assessment of Physicochemical parameters}

Analysis of pharmacological profiles of chemicals is imperative assortments before going for preclinical analysis and these ligands act as promising druggable compounds towards the therapy of various diseases. These consequences shall delineate what are the noticeable functionalities linked with their structures and how these chemical ligands act as drug-like candidates. Therefore, propitious pharmacological properties \& toxicity profiles of molecules were precisely evaluated by molinspiration, DruLiTo software, and Osiris programs. According to table 1, all leads are verified for Pfizer's rule and the obtained parameters revealed that all the chemical molecules can satisfy RO5. Atomic and knowledge-based methods were used to predict the partition coefficient between $\mathrm{n}$-Octanol and water (log Octanol/water) (Malkia et al., 2004) measuring the hydrophobicity of all complexes and it was reported the ranged between 1.49 to 2.46 $(\log \mathrm{P} \leq 5)$ which indicates all molecules are easily permeable. High lipophilic compounds are poorly permeated through membranes, as they get wedged in the lipophilic bilayer. High hydrophilic molecules cannot pass through membranes, as they hardly enter the hydrophobic interior of the lipophilic bilayer (Tsaioun \& Kates, 2013). It is suggestive that the Partition coefficient value must be

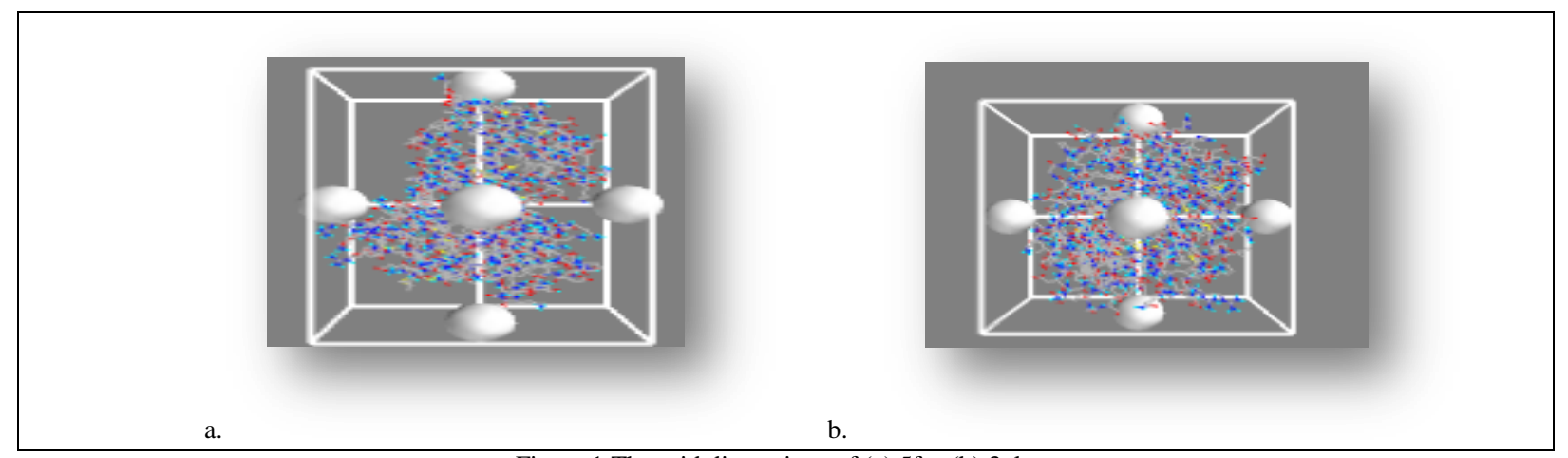

Figure 1 The grid dimensions of (a) 5fee (b) 3gkw.

Journal of Experimental Biology and Agricultural Sciences

http://www.jebas.org 
Table 1 Prediction of Drug properties of best-docked complexes

\begin{tabular}{|c|c|c|c|c|}
\hline & EGCG & Apigenir & Quercetin & Eriodictyol \\
\hline \multicolumn{5}{|c|}{ Physicochemical Properties. } \\
\hline $\log P$ & 2.05 & 2.46 & 1.834 & 1.63 \\
\hline TPSA & 197 & 90.89 & 127.45 & 107.22 \\
\hline MW & 458.08 & 270.24 & 302.04 & 288.06 \\
\hline AMR & 120 & 80.15 & 83.44 & 80.13 \\
\hline nON & 11 & 5 & 7 & 6 \\
\hline n-atoms & 33 & 20 & 22 & 21 \\
\hline noHNH & 8 & 3 & 5 & 4 \\
\hline nviolations & 2 & 0 & 0 & 0 \\
\hline $\mathrm{n}$ rotatable bonds & 4 & 1 & 1 & 1 \\
\hline volume & 367.57 & 224.05 & 240.08 & 238.28 \\
\hline uwQED & 0.158 & 0.755 & 0.467 & 0.629 \\
\hline wQED & 0.197 & 0.722 & 0.458 & 0.618 \\
\hline \multicolumn{5}{|c|}{ Toxicity risks } \\
\hline Mutagenic & None & YES & YES & None \\
\hline Tumorigenic & None & None & YES & None \\
\hline Irritant & None & None & None & None \\
\hline Reproductive effect & None & None & None & None \\
\hline
\end{tabular}

Table 2 Molecular properties of selected macromolecules

\begin{tabular}{|c|c|c|c|}
\hline S. No & Molecular properties & 5FEE & $3 \mathrm{GKW}$ \\
\hline 1 & Classification & Transfer Inhibitor & Immune system \\
\hline 2 & Structure Weight & 37.86 & 48.24 \\
\hline 3 & Molecule & EGFR & EGFR \\
\hline 4 & Chain & $\mathrm{A}$ & $\mathrm{H}$ \\
\hline 5 & Length & 328 & 222 \\
\hline 6 & UniProt ID & P00533 & - \\
\hline \multicolumn{4}{|c|}{ Source } \\
\hline 7 & Organism & Homosapiens & Homosapiens \\
\hline 8 & Common Name & Human & Human \\
\hline \multicolumn{4}{|c|}{ Ligand/Chemical Component } \\
\hline 9 & Identifier & & \\
\hline 10 & Formula & $\mathrm{C} 25 \mathrm{H} 27 \mathrm{~F} 3 \mathrm{~N} 4 \mathrm{O} 2$ & $\mathrm{C}_{10} \mathrm{H}_{22} \mathrm{O}_{6}, \mathrm{C}_{4} \mathrm{H}_{10} \mathrm{O}_{3}$ \\
\hline 11 & Name & $\begin{array}{c}\{\mathrm{N}\}-[\text { 7-methyl-1-[(3 }\{\mathrm{R}\})-1 \text {-propanoylazepan- } \\
\text { 3-yl]benzimidazol-2-yl]-3- } \\
\text { (trifluoromethyl)benzamide }\end{array}$ & $\begin{array}{l}\text { PENTAETHYLENE GLYCOL, } \\
\text { DI(HYDROXYETHYL)ETHER }\end{array}$ \\
\hline
\end{tabular}


less than 5 (Vyas et al., 2013). The calculated values of Log P of these four compounds are within the limit of 5. Toxicity assets of ligands are informative and observable values. The top complexes i.e. Pub Chem CID: 65064, CID: 5280443, CID: 5280343, and CID: 440735 do not show irritation \& reproductive effect, and Pub Chem CID: 5280343 might be tumorigenic. Osiris explorer model for mutagenicity the CID: 65064 (Epigallo Catechin 3-gallate), CID:440735 (Eriodictyol) are non-mutagens, and CID:5280443, CID:5280343 might be mutagens (low reliability).

\subsection{Analysis of macromolecule properties}

Overexpression of this protein receptor (EGFR) has been shown to associate with tumor menace and a bad prognosis for cancer patients (Mendelsohn \& Baselga, 2006). The coordinates of the epidermal growth factor receptor have been deposited at the RCSB Protein data bank with the PDB accession Code: 3GKW \& 5FEE (Talavera et al., 2009). The epidermal growth factor receptor PDB ID: 5FEE contains $2.70 \AA$ resolution and $37.86 \mathrm{MW}$ with one identical chain A, 328 amino acid lengths with 2353 atom count. While the EGFR target PDB entry $3 \mathrm{GKW}$ contains $2.50 \AA$ contain one chain H, 222 amino acid lengths, and 48.24 MW with the source organism Homosapien. They exemplified the molecular properties of both the receptors in table 2 .

\subsection{Drug targets}

A total of selected natural bioactive molecules were identified from the Pub med literature search that showed inhibitory properties of the selected molecules against the breast cancer cells. The 3-Dimensional structures of phytochemicals were downloaded in SDF file format. The structures of both proteins and chemical scaffolds used in this study are presented in figure 2 .

\subsection{Study of Pharmacokinetic \& ADMET properties of compounds}

Pharmacokinetics assets of compounds are informative evident values, which include all competitors to restrain the higher human gastrointestinal absorption (\% HIA). Zhao et al. (2001) stated that most of the absorption data found in the published reports were based on excretion in urine, bioavailability, and oral administration. The most crucial tactic of the chemical \& pharmaceutical industry to
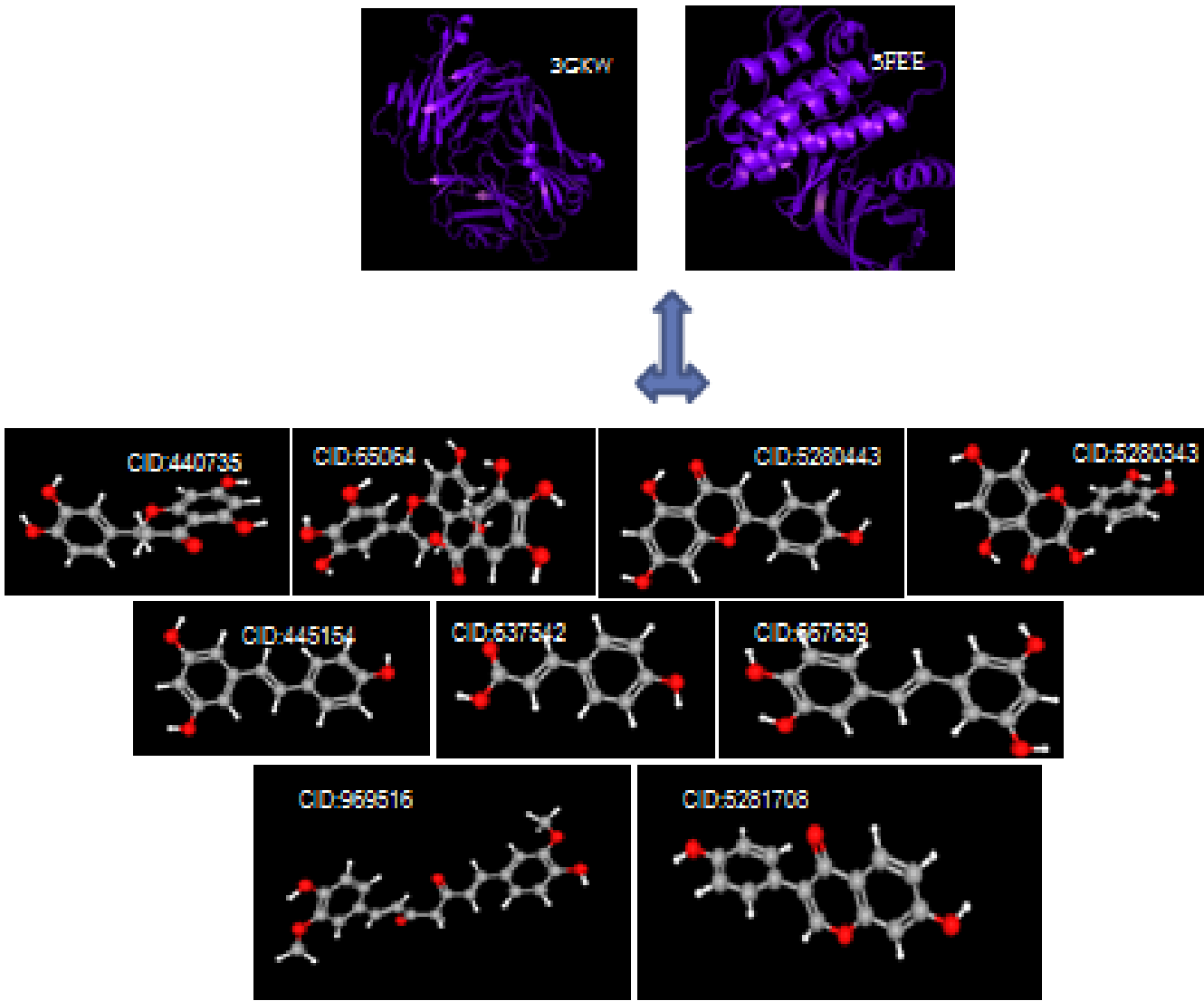

Figure 2 List of chemical structures used in this study

Journal of Experimental Biology and Agricultural Sciences http://www.jebas.org 
overcome its efficacy crisis in drug discovery is to consider the most molecular features for ADME (Nazarshodeh et al., 2015; Wang et al., 2016). Plausible compounds were subjected to ADME, and probability scores assessment using the robust Swiss ADME and ADMETSAR programs. As per the results given in table 3, the pharmacokinetics properties of the top complexes i.e. CID: 65064, CID: 5280443, CID: 5280343 \& Eriodictyol (CID: 440735) were showed good permeability for most of the parameters i.e. Blood-brain barrier coefficient was detected in $0.6047 \& 0.6364$ in best-hit compounds, CID:65064 \& CID: 5280443 compared to other phytochemicals. $\mathrm{CaCo}_{2}$ permeability, HIA (\%), and the major cytochrome enzymes involved through CY450 family genes were also predicted by using structural data (Reichel \& Begley, 1998). Coming to excretion \& toxicity, the obtained results of best hits were recorded as non-carcinogens with good probability scores of $0.9617,0.9181,0.9450, \& 0.9513$ compared to other ligands. The molecules CID: 65064, CID:
5280443 \& CID:440735 having well drug scores, i.e. 0.7, $0.47 \&$ 0.41 when compared to other ligands. The aqueous solubility is significantly affected by solubility. Lower the solubility, the lesser the absorption. The CID:65064 \& CID: 440735 depicted maximum solubility $(-3.52 \&-3.62)$ while the second and third compounds were least soluble when compared to other molecules. The best drug scores, drug-related values such as drug-likeness properties, solubility, and rat oral dose (LD50) were evaluated for individual leads that are entered in figure 3. The pictorial representations of bioavailability radars are shown in figure 5 . The overall findings of the current study revealed that the four docked complexes have the highest binding affinity values and acceptable biological features with less adverse effects; So based on that consequences they may be used as hopeful druggable candidates for human EGFR toward moderating the progression of triple-negative breast cancer (TNBC) and other malignancies associated with the EGFR and their biological pathways.

Table 3 ADMET Profiles of ligand molecules

\begin{tabular}{|c|c|c|c|c|c|c|c|c|}
\hline & 65064 & & 5280443 & & 5280343 & & Eriodictyol & \\
\hline & Result & Probability & Result & Probability & Result & Probability & Result & Probability \\
\hline \multicolumn{9}{|c|}{ Absorption } \\
\hline Blood-Brain Barrier & BBB- & 0.6047 & $\mathrm{BBB}+$ & 0.6364 & BBB- & 0.5711 & BBB- & 0.5784 \\
\hline $\begin{array}{c}\text { Human intestinal } \\
\text { Absorption }\end{array}$ & HIA+ & 0.8867 & HIA+ & 0.9887 & HIA+ & 0.9650 & HIA+ & 0.9223 \\
\hline Caco2 Permeability & Caco2- & 0.8957 & Caco2+ & 0.8541 & Caco2- & 0.8957 & Caco2- & 0.8576 \\
\hline \multicolumn{9}{|c|}{ Distribution \& Metabolism } \\
\hline $\begin{array}{c}\text { CYP4502C9 } \\
\text { Substrate }\end{array}$ & $\begin{array}{c}\text { Non- } \\
\text { substrate }\end{array}$ & 0.8225 & $\begin{array}{c}\text { Non- } \\
\text { substrate }\end{array}$ & 0.7813 & $\begin{array}{c}\text { Non- } \\
\text { substrate }\end{array}$ & 0.7898 & $\begin{array}{c}\text { Non- } \\
\text { substrate }\end{array}$ & 0.7669 \\
\hline $\begin{array}{l}\text { CYP4502D6 } \\
\text { Substrate }\end{array}$ & $\begin{array}{c}\text { Non- } \\
\text { substrate }\end{array}$ & 0.9057 & $\begin{array}{c}\text { Non- } \\
\text { substrate }\end{array}$ & 0.9126 & $\begin{array}{c}\text { Non- } \\
\text { substrate }\end{array}$ & 0.9116 & $\begin{array}{c}\text { Non- } \\
\text { substrate }\end{array}$ & 0.8782 \\
\hline $\begin{array}{l}\text { CYP4503A4 } \\
\text { Substrate }\end{array}$ & $\begin{array}{c}\text { Non- } \\
\text { substrate }\end{array}$ & 0.6299 & $\begin{array}{c}\text { Non- } \\
\text { substrate }\end{array}$ & 0.6907 & $\begin{array}{c}\text { Non- } \\
\text { substrate }\end{array}$ & 0.6530 & $\begin{array}{c}\text { Non- } \\
\text { substrate }\end{array}$ & 0.5849 \\
\hline $\begin{array}{l}\text { CYP inhibitor } \\
\text { promiscuity }\end{array}$ & $\begin{array}{c}\text { Low CYP } \\
\text { Inhibitory } \\
\text { Promiscuity }\end{array}$ & 0.8067 & $\begin{array}{c}\text { High CYP } \\
\text { Inhibitory } \\
\text { Promiscuity }\end{array}$ & 0.7316 & $\begin{array}{c}\text { High CYP } \\
\text { Inhibitory } \\
\text { Promiscuity }\end{array}$ & 0.5822 & $\begin{array}{c}\text { Low CYP } \\
\text { Inhibitory } \\
\text { Promiscuity }\end{array}$ & 0.5488 \\
\hline \multicolumn{9}{|c|}{ Excretion \& Toxicity } \\
\hline $\begin{array}{l}\text { Human Ether-a-go- } \\
\text { go-related gene } \\
\text { inhibition }\end{array}$ & $\begin{array}{c}\text { Weak } \\
\text { inhibitor }\end{array}$ & 0.9847 & $\begin{array}{c}\text { Weak } \\
\text { inhibitor }\end{array}$ & 0.9559 & $\begin{array}{c}\text { Weak } \\
\text { inhibitor }\end{array}$ & 0.9781 & $\begin{array}{c}\text { Weak } \\
\text { inhibitor }\end{array}$ & 0.9756 \\
\hline AMES Toxicity & $\begin{array}{l}\text { Non-Ames } \\
\text { toxic }\end{array}$ & 0.9040 & $\begin{array}{l}\text { Non-Ames } \\
\text { toxic }\end{array}$ & 0.8906 & $\begin{array}{l}\text { Non-Ames } \\
\text { toxic }\end{array}$ & 0.7220 & $\begin{array}{l}\text { Non-Ames } \\
\text { toxic }\end{array}$ & 0.7215 \\
\hline Carcinogens & $\begin{array}{c}\text { Non- } \\
\text { carcinogens }\end{array}$ & 0.9617 & $\begin{array}{c}\text { Non- } \\
\text { carcinogens }\end{array}$ & 0.9181 & $\begin{array}{c}\text { Non- } \\
\text { carcinogens }\end{array}$ & 0.9450 & $\begin{array}{c}\text { Non- } \\
\text { carcinogens }\end{array}$ & 0.9513 \\
\hline Acute oral toxicity & IV & 0.3764 & III & 0.7012 & II & 0.7348 & II & 0.4796 \\
\hline
\end{tabular}




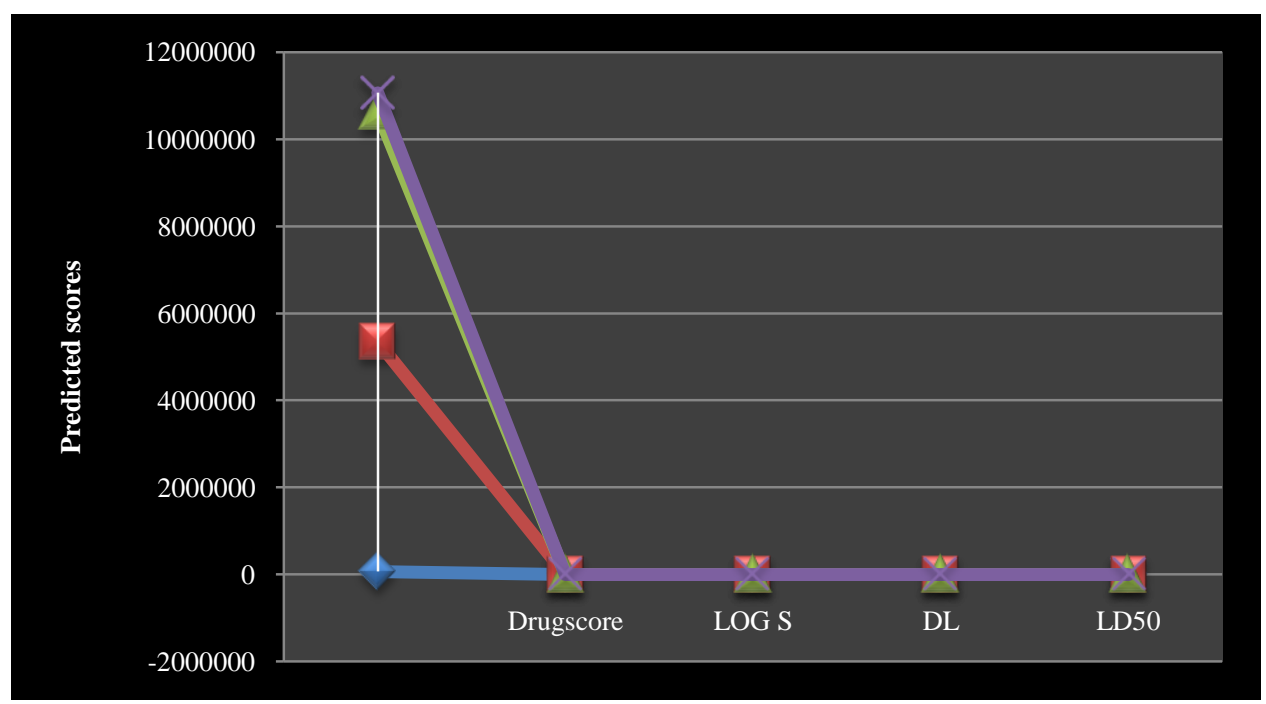

Figure 3 Drug properties of best virtual leads

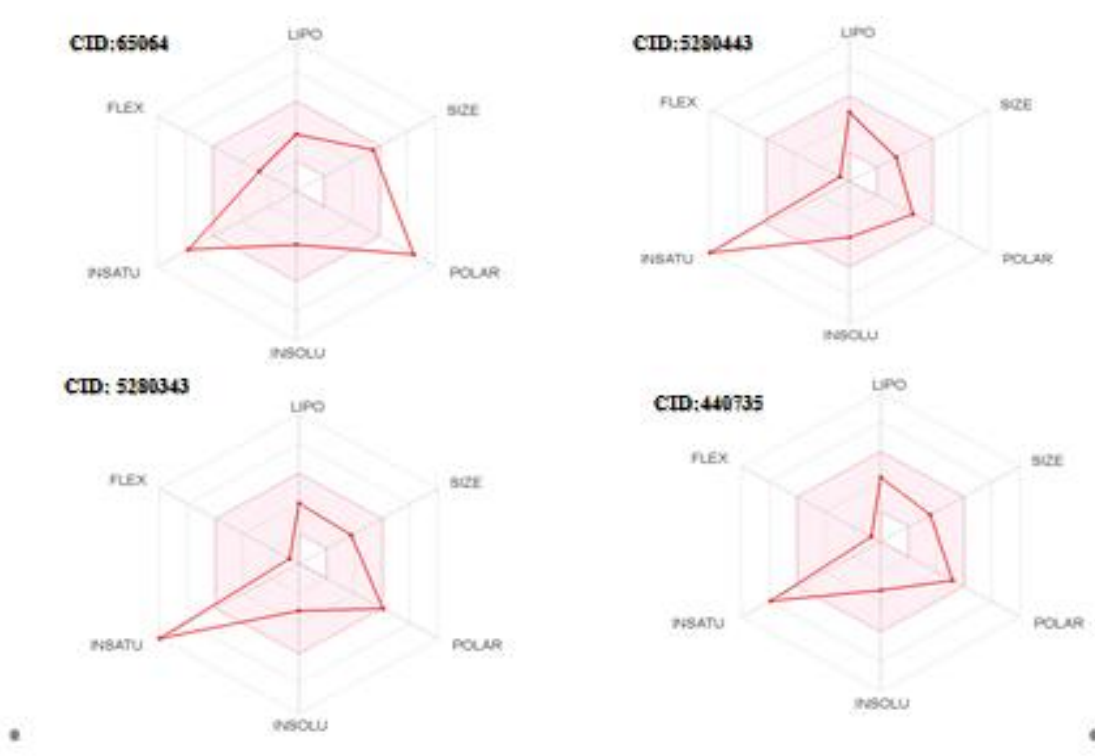

Figure 5 The bioavailability radars of the best virtual hits

3.5 Visualization of screening results of proteins and bioactive ligand molecules

The virtual screening of ligands with a protein target of EGFR (5FEE $\& 3 \mathrm{GKW}$ ) is used by employing AD Vina in the PyRx interface, and the outcomes were imaged by utilizing the Pymol visualization tool (figure 4). Out of nine active bio compounds i.e., Pub Chem CID: 440735; CID: 445154; CID: 65064; CID: 667639; CID: 637542; CID: 969516; CID: 5280343; CID: 5280443; CID: 5281708. Among these phytochemicals, five docking scaffolds showed the least minimum binding affinity values, i.e. -5.6, -6.6, -7.0, -7.0, and -7.7 $\mathrm{kcal} / \mathrm{mol} \Delta \mathrm{G}$ binding energies with the $5 \mathrm{FEE}$ receptor. Whereas three complexes showed minimum binding energy values, i.e. -5.7, -7.0, 7.1, with the target protein PDB ID: 3GKW compared to other molecules used in these studies. The top four molecules, i.e. CID:65064 (EGCG); CID:440735 ((S)-2- (3,4-dihydroxy phenyl)5,7-dihydroxychroman-4-one); CID: $5280343 \quad\left(3,3^{\prime}, 44^{\prime}, 5,7-\right.$ Pentahydroxyflavone); CID: $5280443 \quad$ (5,7-Dihydroxy-2-(4hydroxyphenyl)-4H-chromen-4-one) displayed the highest binding affinities and showed inhibitory activity against breast cancer. 


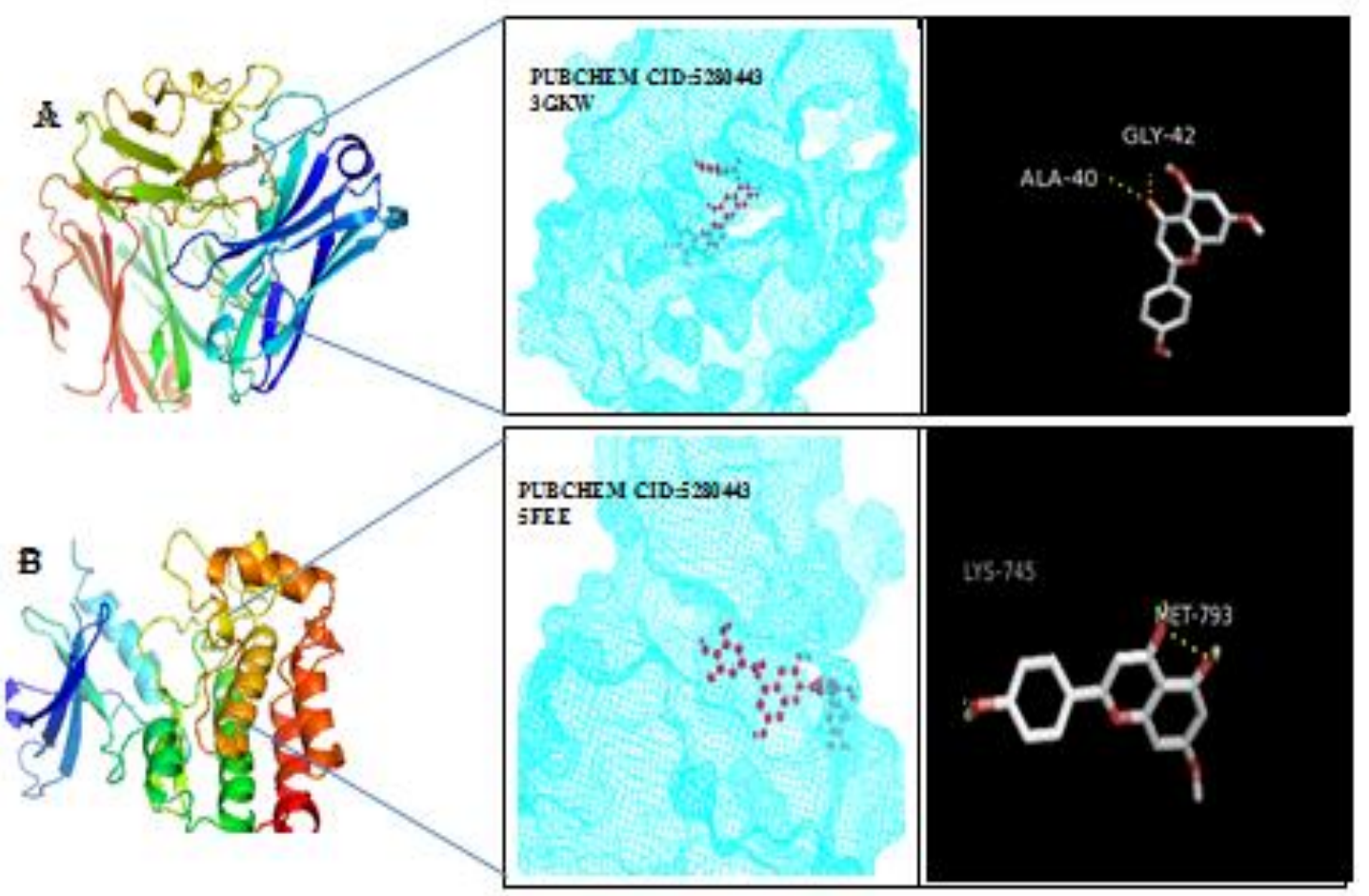

소
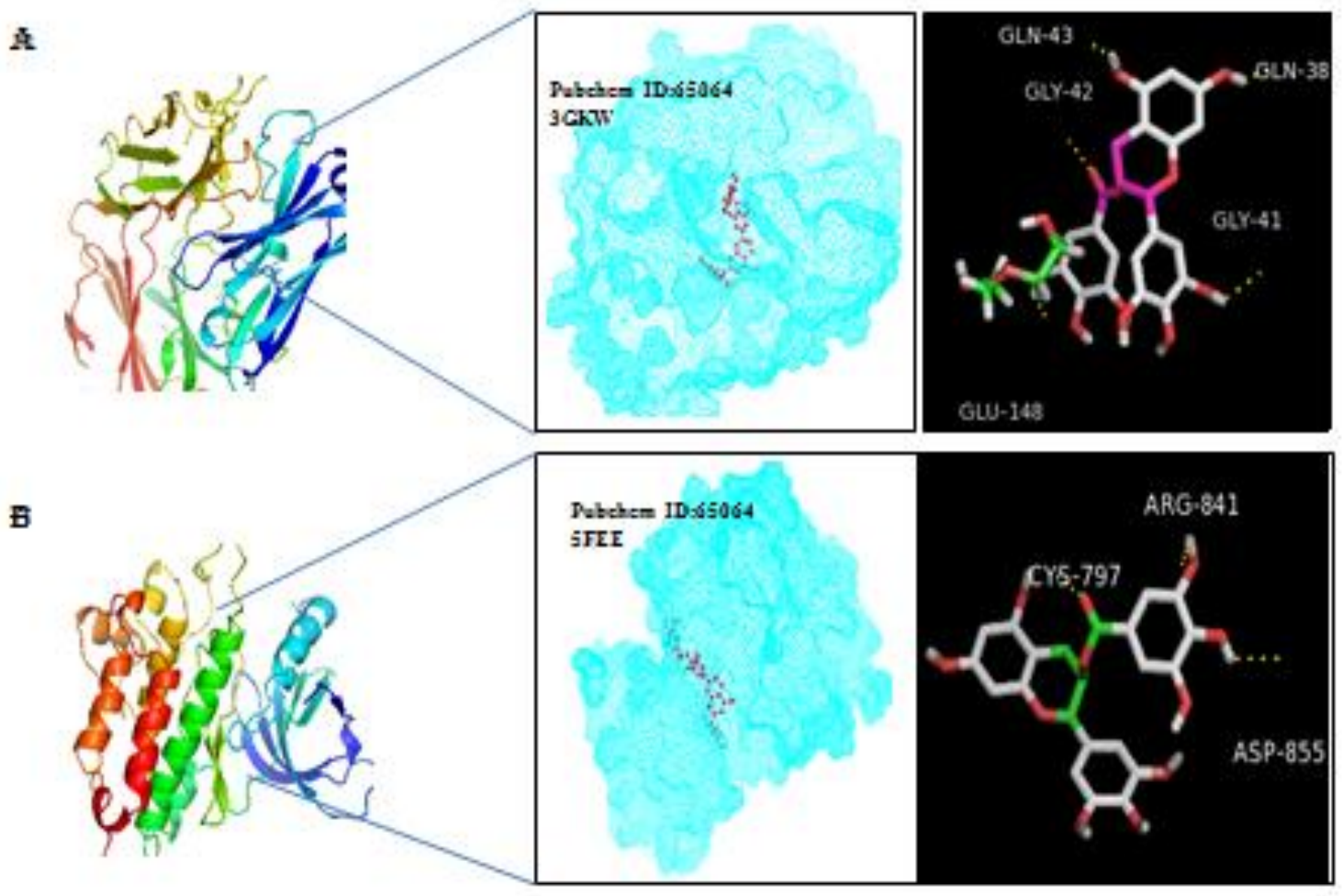

Figure 4 Visualization of top docked complexes

Journal of Experimental Biology and Agricultural Sciences http://www.jebas.org 
Table 4 Binding affinities of ligand molecules that can be used in these study

\begin{tabular}{|c|c|c|c|c|c|}
\hline \multirow[t]{2}{*}{$\begin{array}{l}\text { Pubchem } \\
\text { ID }\end{array}$} & \multirow[t]{2}{*}{$\begin{array}{l}\text { Molecule name } \\
\quad \text { (IUPAC) }\end{array}$} & \multicolumn{2}{|c|}{$\begin{array}{l}\Delta \mathrm{G} \text { binding energy } \\
(\mathrm{kcal} / \mathrm{mol})\end{array}$} & \multicolumn{2}{|c|}{ Interacting residues } \\
\hline & & 5FEE & $3 \mathrm{GKW}$ & 5FEE & $3 \mathrm{GKW}$ \\
\hline $440735^{*}$ & $\begin{array}{l}\text { (2S)-2-(3,4-dihydroxyphenyl)-5,7- } \\
\text { dihydroxy-2,3-dihydrochromen-4-one. }\end{array}$ & -7.7 & -8.1 & $\mathrm{MET}^{793}, \mathrm{LYS}^{745}$ & $\mathrm{GLY}^{42}, \mathrm{GLN}^{43}$ \\
\hline 445154 & $\begin{array}{c}\text { 5-[(E)-2-(4- } \\
\text { hydroxyphenyl)ethenyl]benzene-1,3- } \\
\text { diol. }\end{array}$ & -6.6 & 7.0 & $\mathrm{THR}^{854}, \mathrm{PRO}^{794}$ & $\mathrm{GLN}^{42}$ \\
\hline $65064^{*}$ & $\begin{array}{c}\text { [(2R,3R)-5,7-dihydroxy-2-(3,4,5- } \\
\text { trihydroxyphenyl)-3,4-dihydro-2H- } \\
\text { chromen-3-yl] 3,4,5-trihydroxybenzoate. }\end{array}$ & -8.6 & -8.4 & $\mathrm{ASP}^{855}, \mathrm{CYS}^{797}, \mathrm{ARG}^{841}$ & $\begin{array}{c}\mathrm{GLY}^{42}, \mathrm{GLN}^{38}, \mathrm{GLY}^{41}, \mathrm{GLU} \\
{ }^{148}, \mathrm{GLN}^{43}\end{array}$ \\
\hline 667639 & $\begin{array}{c}\text { 4-[(E)-2-(3,5- } \\
\text { dihydroxyphenyl)ethenyl]benzene-1,2- } \\
\text { diol. }\end{array}$ & -7.0 & -7.1 & $\begin{array}{c}\mathrm{GLY}^{917}, \mathrm{ILE}^{918}, \\
\mathrm{TYR}^{915}, \mathrm{ARG}^{841}, \mathrm{SER}^{912}\end{array}$ & $\mathrm{THR}^{39}, \mathrm{GLY}^{42}, \mathrm{SER}^{7}$ \\
\hline 637542 & $\begin{array}{l}\text { (E)-3-(4-hydroxyphenyl) prop-2-enoic } \\
\text { acid. }\end{array}$ & -5.6 & -5.7 & $\mathrm{LEU}^{760}$ & SER $^{10}$ \\
\hline 969516 & $\begin{array}{c}\text { (1E,6E)-1,7-bis(4-hydroxy-3- } \\
\text { methoxyphenyl)hepta-1,6-diene-3,5- } \\
\text { dione } \\
\end{array}$ & -7.0 & 7.6 & - & $\mathrm{SER}^{7}, \mathrm{LYS}^{103}$ \\
\hline $5280343^{*}$ & $\begin{array}{l}\text { 2-(3,4-dihydroxyphenyl)-3,5,7- } \\
\text { trihydroxychromen-4-on }\end{array}$ & -7.7 & -7.6 & $\mathrm{MET}^{793}, \mathrm{LYS}^{745}, \mathrm{LEU}^{718}$ & $\mathrm{GLN}^{43}, \mathrm{GLN}^{42}, \mathrm{ALA}^{40}$ \\
\hline $5280443^{*}$ & $\begin{array}{c}\text { 5,7-dihydroxy-2-(4- } \\
\text { hydroxyphenyl)chromen-4-one }\end{array}$ & -7.7 & -8.3 & $\mathrm{LYS}^{745}, \mathrm{MET}^{793}$ & $\mathrm{ALA}^{40}, \mathrm{GLY}^{42}$ \\
\hline 5281708 & $\begin{array}{c}\text { 7-hydroxy-3-(4- } \\
\text { hydroxyphenyl)chromen-4-one }\end{array}$ & -7.1 & -7.6 & $\mathrm{LYS}^{745}, \mathrm{GLU}^{762}$ & $\mathrm{GLY}^{42}$ \\
\hline
\end{tabular}

3.6 Binding mode analysis of best natural compounds with the protein structure

In this regard, the current study identified four Pub Chem compounds i.e., [(2R,3R)-5,7-dihydroxy-2-(3,4,5-trihydroxyphenyl)3,4-dihydro-2H-chromen-3-yl] 3,4,5-trihydroxybenzoate (CID:65064); 5,7-dihydroxy-2-(4-hydroxyphenyl)chromen-4-one (CID:5280443); 2-(3,4-dihydroxyphenyl)-3,5,7-trihydroxychromen4-one (CID:5280343); (2S)-2-(3,4-dihydroxyphenyl)-5,7-dihydroxy2,3-dihydrochromen-4-one (CID:440735) might be chosen as novel inhibitors for EGFR and these compounds having antitumor properties and have the high human epidermal growth factor receptor protein binding capability. The structures of these natural molecules with EGFR (5FEE) CID: 65064 having good binding energy value i.e.-8.6 kcal $/ \mathrm{mol}$. These shown interactions with $\mathrm{ASP}^{855}, \mathrm{CYS}^{797}$, and $\mathrm{ARG}^{841}$. CID:5280443 contains a binding energy value of $-7.7 \mathrm{kcal} / \mathrm{mol}$ this was shown to interact with $\mathrm{LYS}^{745}$, MET ${ }^{793}$. CID: 440735 having a better affinity value i.e. $-7.7 \mathrm{kcal} / \mathrm{mol}$, this shows the interaction with $\mathrm{MET}^{793}$, $\mathrm{LYS}^{745}$, and another EGFR Protein (3GKW) CID: 65064 having ameliorated affinity value is -8.4 $\mathrm{kcal} / \mathrm{mol}$. This was shown to interact with $\mathrm{GLY}^{42}, \mathrm{GLN}^{38}$, $\mathrm{GLY}^{41}$, GLU ${ }^{148}$, and $\mathrm{GLN}^{43}$. CID: 5280443 having a binding energy value is $-8.3 \mathrm{kcal} / \mathrm{mol}$. This was shown an interaction with $\mathrm{ALA}^{40}$ and $\mathrm{GLY}^{42}$. The interacting residues and binding energy values of all compounds that can be used in this study are elucidated in table 4 . The receptor and ligand interacting residues of top complexes are shown in figure 4. Hopefully, these results may be used for novel breast cancer drugs against EGFR.

\section{Conclusion}

The present study recognized the potential medication that emphasis against the target protein (EGFR) as a characteristic solution to prevent breast carcinoma. The focal objective of the virtual screening and in silico based assessments used in this study was to portray as rational strategies for recognition of novel natural inhibitors for human EGFR. The binding affinity values and the interacting residues of the protein-ligand complexes showed that 2 natural compounds have greater binding affinities, respectable drug scores, and fewer adverse health effects. Based on these criteria, it can be suggested that the characterized leads may act as intense druggable inhibitors against EGFR and can be used as anticancerous agents to treat breast cancer. It can be concluded that our novel comparative strategies can reveal potential leads and nontoxic molecules that may proficiently act as promising templates against EGFR for reducing TNBC. The research work will be continued on cell lines in wet biology experiments and then in vivo studies. 


\section{Acknowledgments}

MK is thankful to the university grants commission, New Delhi, for financial support in the form of the UGC-BSR (RFSMS) Senior Research Fellowship. YS is thankful to Human Resource Development for Health Research, New Delhi (F.No.V.25011/542HRD/2016-HR).

\section{Conflict of interest}

No conflict of interest is associated with this work.

\section{References}

Abhay PM, Bahare SMN, Bilge S, Mehtap K, Mehdi SR, Patrick VTF, Natália M, Javad SR (2018) Resveratrol: A Double-Edged Sword in Health Benefits. Biomedicines 6(3):91.

Alok R, Sharavan R, Nehal G, Itishree K, Stephen W, Suyash S, Hiranmoy D, Sangeeta S, Sahdeo P, Sanjay K(2019) Role of Phytochemicals in Cancer Prevention. International of Journal Molecular Sciences 20(20):4981.

Amaia EM, Mehmet KT, Niebert M, Klockenbring T, Zeppernick F, Gattenlöhner S, Heerlein IM, Hussain AF (2019) Molecular Targeting Therapy against EGFR Family in Breast Cancer: Progress and Future Potentials. Cancers (Basel) 11(12):1826.

Bahare S, Abhay PM, Manisha N, Bilge S, Mehtap K, Mehdi SR, Patrick VTF, Natália M, Javad SR (2018) Resveratrol: A DoubleEdged Sword in Health Benefits. Biomedicines 6(3):91.

Benson JR, Jatoi I (2012) The global breast cancer burden. Future Oncology 8(6): 697-702.

Berman AY, Motechin RA, Wiesenfeld MY, Holz MK (2017) The therapeutic potential of resveratrol: A review of clinical trials. NPJ Precision Oncology 1:35.

Cheng F, Li W, Zhou Y, Shen J, Wu Z, Liu G, Lee PW, Tang Y (2012) AdmetSAR: a comprehensive source and free tool for assessment of chemical ADMET properties. Journal of Chemical Information and Modeling 52: 3099-105.

Clavin M, Gorzalczany S, Macho A, Gorzalczany S, Macho A, Muñoz E, Ferraro G, Acevedo C, Martino V (2007) Antiinflammatory activity of flavonoids from Eupatorium arnottianu. Journal of Ethno Pharmacology 112 (3):585-9.

Dai X, Xiang L, Li T, Bai Z (2016) Cancer Hallmarks, Biomarkers and Breast Cancer Molecular Subtypes. Journal of Cancer 7(10):1281-1294.

Daina A, Michelin O, Zoete V (2017) Swiss ADME: a free web tool to evaluate pharmacokinetics, drug-likeness and medicinal chemistry friendliness of small molecules. Scientific Reports 7: (42717) 1-13.

Dallakyan S, Olson AJ (2015) Small-molecule library screening by docking with PyRx. Chemical Biology 1263:243-250.

Hyuna S, Jacques FME, Rebecca L, Siegel MPH, Mathieu L, Isabelle S, Ahmedin Jemal DMV, Freddie B (2021) Global Cancer Statistics 2020: GLOBOCAN Estimates of Incidence and Mortality Worldwide for 36 Cancers in 185 Countries. CA: A Cancer Journal for Clinicians 71(3):209-249.

John MP (2019) Resveratrol: Twenty Years of Growth, Development, and Controversy. Biomolecules \& Therapeutics (Seoul) 27(1):1-14.

Lambert JD, Elias RJ (2010) The antioxidant and pro-oxidant activities of green tea polyphenols: A role in cancer prevention. Achieves of Biochemistry and Biophysics 501:65-72.

Li M, Kildegaard KR, Chen Y, Rodriguez A, Borodina I, Nielsen J (2015) De novo production of resveratrol from glucose or ethanol by engineered Saccharomyces cerevisiae. Metabolic Engineering 32:1-11.

Lill MA, Danielson ML (2011) Computer-aided drug design platform using PyMOL. Journal of Computer-Aided Molecular Designing 25:13-19.

Lipinski, CA, Lombardo F, Dominy BW, Feeney PJ (2001) Experimental and computational approaches to estimate solubility and permeability in drug discovery and development settings. Advanced Drug Delivery Reviews 46 (1-3): 3-26.

Mälkiä A, Murtomäki L, Urtti A, Kontturi K (2004) Drug permeation in biomembranes: in vitro and in silico prediction and influence of physicochemical properties. European Journal of Pharmaceutical Sciences 23(1):13-47.

Marín L, Gutiérrez-del-Río I, Yagüe P, Manteca A, Villar CJ, Lombó F (2017) De novo biosynthesis of apigenin, luteolin, and eriodictyol in the actinomycete Streptomyces albus and production improvement by feeding and spore conditioning. Frontiers in Microbiology 8: 921.

Mendelsohn J, Baselga J (2006) Epidermal growth factor receptor targeting in cancer. Seminars in Oncology 33 (4): 369-85.

Musial C, Kuban JA, Gorska PM (2020) Beneficial Properties of Green Tea Catechin. International Journal of Molecular Sciences 21(5): 1744 .

National Centre Registry Programme (2016) Three-year report of population-based Cancer registries and projections of burden of 
Cancer (report of 27 PBCRs in India). Bangalore: Indian Council of Medical Research-National Centre for Disease Informatics and Research (ICMR-NCDIR).

Nawaz W, Zhou Z, Deng S, Ma X, Ma X, Li C, Shu X (2017) Therapeutic versatility of resveratrol derivatives. Nutrients 9:1188.

Nazarshodeh E, Shiri F, Ghasemi JB (2015) 3D-QSAR and virtual screening studies in identification of new Rho-kinase inhibitors with different scaffolds. Journal of Iranian Chemical Society 12:1945-1959.

Pymol (2015) Available online: http://www.pymol.org/ Accessed on 9 May 2015.

Reichel A, Begley DJ (1998) Potential of immobilized artificial membranes for predicting drug penetration across the blood-brain barrier. Pharmaceutical Research 15:1270-1274.

Roca P, Sastre-Serra J, Nadal-Serrano M, Pons DG, BlanquerRossello MD, Oliver J (2014) Phytoestrogens and Mitochondrial Biogenesis in Breast Cancer. Influence of Estrogen Receptors Ratio. Current Pharmaceutical Design 20: 5594-5618.

Sandipan C, Anait SL, Pradip KB (2013) Structural insights into Resveratrol's antagonist and partial agonist actions on estrogen receptor alpha. BMC Structural Biology v13: 27.

Sinha D, Sarkar N, Biswas J, Bishayee A (2016) Resveratrol for breast cancer prevention and therapy: Preclinical evidence and molecular mechanisms. Seminars in Cancer Biology 40-41:209-232.

Sumio H, Tomokazu O, Noriyuki M, Yumiko O, Yoriyuki N, Mamoru I (2020) Anti-Cancer Effects of Green Tea Epigallocatchin-3-Gallate and Coffee Chlorogenic Acid. Molecules 25: 4553.

Talavera A, Friemann R, Gómez-Puerta S, Martinez-Fleites C, Garrido G, Rabasa A, Requena AL, Pupo A, Johansen RF, Sánchez O, Krengel U, Moreno E (2009) Nimotuzumab, an Antitumor Antibody that Targets the Epidermal Growth Factor Receptor, Blocks Ligand Binding while Permitting the Active Receptor Conformation. Cancer research 69(14): 5851-5859.
Tsaioun K, Kates SA (2013) ADMET for medicinal chemists: a practical guide. John Wiley \& Sons.

Vyas VK, Ghate M, Goel A (2013) Pharmacophore modeling, virtual screening, docking and in silico ADMET analysis of protein kinase B (PKB b) inhibitors. Journal of Molecular Graphics \& Modelling 42:17-25.

Wahab A, Gao K, Jia C, Zhang F, Tian G, Murtaza G, Chen J (2017) Significance of resveratrol in clinical management of chronic diseases. Molecules 22:1329.

Wamidh HT, Izzeddin A, Safa D, Reem FA, Asma IM (2020) Plant-Derived Natural Products in Cancer Research: Extraction, Mechanism of Action, and Drug Formulation. Molecules 25(22): 5319.

Wang NN, Dong J, Deng Y-H, Zhu MF, Wen M, Yao ZJ, Lu AP, Wang JB, Cao DS (2016) ADME properties evaluation in drug discovery: prediction of Caco-2 cell permeability using a combination of NSGA-II and boosting. Journal of Chemical Information and Modeling 56:763-773.

World Cancer Report (2014) World Health Organization: IARC Publications.

Xiao Q, Zhu W, Feng W, Lee SS, Leung AW, Shen J, Gao L, Xu CA (2019) Review of Resveratrol as a Potent Chemo protective and Synergistic Agent in Cancer Chemotherapy. Frontiers Pharmacology 9:1534.

Yao K, PanPan Ye, Li Zhang, Jian Tan, XiaJing Tang, YiDong Zhang (2008) Epigallo Catechin gallate protects against oxidative stress-induced mitochondria-dependent apoptosis in human lens epithelial cells. Molecular vision 14:217-223.

Zhao YH, Le J, Abraham MH, Hersey A, Eddershaw PJ, Luscombe CN, Butina D, Beck G, Sherborne B, Cooper I, Platts JA (2001) Evaluation of human intestinal absorption data and subsequent derivation of a quantitative structure-activity relationship (QSAR) with the Abraham descriptors. Journal of Pharmaceutical Sciences 90(6):749-784. 